\title{
¿'Más allá del norte y del sur? Migración, informalización y revitalización sindical
}

\author{
Ronaldo Munck \\ (traducción del inglés de Luis Rodolfo Morán Quiroz)
}

Resumen. Este artículo aborda tanto los desafíos como las oportunidades que plantea la migración laboral para el movimiento organizado de la clase trabajadora. La fuerza de trabajo ha sido reestructurada en el último cuarto de siglo, pero ahora hay señales de una recomposición de la fuerza de trabajo a medida que los sindicatos buscan diferentes caminos hacia la revitalización. Cada vez más, el movimiento de los trabajadores que trasciende las fronteras nacionales puede generar divisiones y ser utilizado para debilitar los estándares laborales existentes; sin embargo, planteamos también la posibilidad de que constituya una fuente de revitalización sindical, al permitir la llegada de nuevos miembros, con nuevas ideas.

Palabras clave: migración laboral, sindicatos, movimientos sociales, globalización, estándares laborales.

\begin{abstract}
Aвstract. This article takes up both the challenges and opportunities that labor migration poses for the organized labor movement. Labor has been dramatically restructured over the last quarter of a century, but there are now signs of labor recomposition as trade unions seek different paths toward revitalization. Increasingly, the movement of workers across national boundaries might create divisions, and it will be deployed to undermine existing labor standards. But we pose also the possibility that it might be a source of trade union revitalization, bringing in new members with new ideas but also creating a dynamic for raising labor standards rather than lowering them. In brief, internationalism begins at home.
\end{abstract}

KEYWORDs: labor migration, unions, social movements, globalization, labor standards.

Ronaldo Munck es jefe de Participación Cívica y Global en la Dublin City University de Irlanda y profesor de Estudios Latinoamericanos en la Universidad de Liverpool, Inglaterra. 


\section{INTRODUCCIÓN}

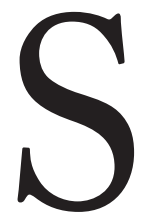

e podría argumentar que el malestar económico global desatado por la crisis bancaria en Estados Unidos en 2007 y su difusión viral subsecuente en el mundo derivarán en una profundización, más que en una retirada, de la globalización. Quizá estamos por llegar a un mundo «más allá del Norte y del Sur» en términos económicos y políticos. Después de todo, algunos de los países del B RIC — Brasil, Rusia, India y China- están ahora en posición de ser parte del nuevo sistema de gobierno global. La crisis económica parece más profunda en las viejas tierras de origen del capitalismo en el Norte, mientras que en el Sur se presenta en el horizonte una etapa de desarrollo más dinámica. Mi perspectiva sobre esta cuestión parte «desde abajo», es decir, se pregunta si el movimiento de los trabajadores podría revitalizarse si adoptara las nuevas prácticas laborales de la mano del creciente movimiento de trabajadores que atraviesan las fronteras nacionales.

El primer momento del argumento, referente al trabajo reestructurado, presenta de manera sucinta la decisiva reelaboración de la condición de la fuerza de trabajo en el último cuarto de siglo. En relación con la flexibilización, la informalización, la desregulación y el surgimiento de lo que algunos han llamado precariado, es decir, un proletariado precario, se podría argumentar que en la actualidad constituyen elementos de un proceso mundial que no puede confinarse al que todavía se hace referencia, anacrónicamente, como el mundo «subdesarrollado» del Sur global. En torno a los movimientos laborales se aborda, en un segundo momento, el tema de la creciente movilización laboral allende las fronteras nacionales en las décadas recientes bajo la égida de la globalización. En teoría, este proceso debiera conducir al debilitamiento de las condiciones de la fuerza de trabajo al dar ventaja al capital. También se analiza cómo el trabajo precario es acompañado, con mayor frecuencia, de una forma igualmente precaria de ciudadanía para la mayoría de los migrantes. Pero, por otro lado, ¿qué pasa si los pasos incipientes hacia la revitalización sindical —la 
fuerza de trabajo emergente, el tercer argumento que se presenta aquí- comienza a dar pie a una práctica de «el internacionalismo comienza en casa» y a priorizar la organización de este nuevo precariado? Al igual que con las dos secciones anteriores, las principales lecciones provienen del Sur global, donde los sindicatos han abordado creativamente en el pasado los flujos migratorios internos. Si algo aprendimos de la recesión global de 2008-2009 fue que debemos ir más allá y «trascender el Norte y el Sur» en términos de un análisis unificado, orientado a la fuerza de trabajo y a construir los movimientos sociales globales de oposición que se han configurado en respuesta al dominio del libre mercado autorregulado durante los últimos 25 años.

\section{LA FUERZA DE TRABAJO REESTRUCTURADA}

La consecuencia no intencionada de la utopía neoliberal del libre mercado es la brasilización del occidente [...] la expansión del empleo temporal e inseguro, la discontinuidad y la informalidad laxa hacia las sociedades occidentales que hasta el momento habían sido los bastiones del pleno empleo (Beck, 2000: 1).

Cuando los sociólogos alemanes han comenzado a preocuparse por la «brasilización» de su, hasta entonces, sociedad de pleno empleo, desarrollada y avanzada, podemos suponer que se han estado generando algunos cambios significativos. Las relaciones de producción precarias, inseguras o informales afectaban alrededor de una décima parte de los empleados en la Alemania de los años sesenta, empero, esa cifra se ubica ahora en casi $40 \%$ y va en aumento. Cabe preguntarnos, por tanto, si Brasil nos muestra ahora el futuro de Alemania, en una dramática inversión del dictum clásico de Marx que decía que la Inglaterra industrializada mostraba al resto del mundo el futuro. 
Antes de que se convirtiera en parte de las corrientes dominantes (occidentalización) la distinción entre el sector formal y el informal, en los años setenta (véase Hart, 1973) ya se había dado un fuerte debate en América Latina en torno al concepto de «marginalidad». La teoría dominante de la modernización de los años cincuenta y sesenta encontraba difícil dar cuenta de la gran cantidad de migrantes internos subempleados que rodeaban a las ciudades capitales con sus viviendas improvisadas y que parecían situarse de manera «marginal», en todos los sentidos, de la modernización de la sociedad. Incluso, desde el campo marxista, algunos autores como José Nún (1969), argumentaban que los pobres marginales eran «disfuncionales» al sistema de desarrollo capitalista dependiente. A diferencia del «ejército industrial de reserva» clásico en el marxismo, los nuevos pobres urbanos, con fundamento en los migrantes, no eran ni siquiera potencialmente útiles, eran simplemente marginales para el régimen de acumulación capitalista, o así rezaba el argumento. Gradualmente, se estableció una crítica de esta perspectiva marxista de la modernización y fue reemplazada por una perspectiva más aterrizada y positiva.

Fue el teórico social brasileño Chico de Oliveira quien mostró con mayor claridad, en su Crítica de la razón dualista (Oliveira, 1972), que las actividades del llamado sector marginal de hecho estaban generadas por, y resultaban rentables para, el sistema capitalista moderno. El comercio en pequeña escala facilitaba la distribución de bienes industriales y las viviendas autoconstruidas de las villas-miseria simplemente ahorraban al capital el costo de la producción de casas. Más ampliamente, el sector informal urbano (la autoempleada pequeña burguesía, al igual que el proletariado informal) habría de verse como elemento que subsidia la acumulación capitalista a través de sus altos niveles de autoexplotación. Más que el enfoque en un «sector informal» (que le da una unidad y coherencia que simplemente no posee), quizá deberíamos poner más atención al proceso de informalización, una tendencia que ahora se acentúa en la era de la globalización a medida que el trabajo está cada vez más desregulado y los trabajadores son más desposeídos. 
En términos más amplios, podemos mostrar que el dualismo explícito de la distinción formal/informal adolece de severas debilidades analíticas. Plantea dos sectores herméticamente sellados, que simplemente no pueden distinguirse en la práctica y es incapaz de ver categorías intermedias o híbridas de empleo. Ello no niega la importancia de una relación no regulada/ informal de la producción ni la generación de ingresos que no es «marginal» para el desarrollo capitalista, sino que es un elemento integral de su dinámica. El punto a resaltar es que estas relaciones y procesos no son una secuela desafortunada de una época premoderna o el dudoso privilegio exclusivo de las economías «subdesarrolladas». Cumplen, en cambio, una función clave para el capital al debilitar el poder social de la clase trabajadora y al atomizar la fuerza de trabajo. El Banco Mundial está simplemente equivocado, tanto en la teoría como en la práctica, cuando afirma que «el sector informal se encoge con el desarrollo» (Banco Mundial, 1995: 35). El desarrollo desigual pero también combinado del capitalismo ha llevado la producción de la alta tecnología al Sur global, pero al mismo tiempo también reproducirá y expandirá a nivel mundial las llamadas prácticas informales de trabajo.

Hoy en día, podemos referirnos a una clase trabajadora informal global que, según Davis, «es de aproximadamente mil millones, convirtiéndose en la clase social de más rápido crecimiento y con los menores precedentes en la tierra» (Davis, 2007: 178). La crisis de los años ochenta derivó en un crecimiento masivo en el llamado trabajo informal, que era lo único que se interponía entre los pobres que trabajaban y la muerte de hambre en el Sur global. Pero también proporciona ahora lo que Davis llamó «una fuerza de trabajo secreta para la economía formal» (Davis, 2007: 178) en el Norte, similares a Wal-Mart y otras compañías multinacionales que generan cadenas mercantiles que se incrustan profundamente en el sector informal en el Sur global. Lo que vemos ahora es un patrón más allá de la división formal/informal o Norte/Sur con un continuo que se profundiza en la fuerza de trabajo cada vez más informalizada del Sur global y en las economías inmersas en la recesión en el Norte. 
Con miras a desarrollar un movimiento de trabajadores vinculado a esta nueva clase trabajadora informal global, debemos ir más allá de las nociones norte-atlánticas en el sentido de reducirlo a un fenómeno puramente del Sur. En 2004, la Organización Internacional del Trabajo (OIT) realizó un estudio mundial global de la seguridad económica y encontró que tres cuartas partes de la población mundial vivían en circunstancias de inseguridad económica (oIT, 2004). El término precariado — una amalgama de la noción clásica del proletariado con el adjetivo precarización, que significa generar una vida más precaria - está diseñado, en esencia, para captar la norma creciente del trabajo inseguro. Hay poca seguridad en términos de tenencia del empleo, condiciones de trabajo, derechos laborales y, efectivamente, de la vida misma para un número creciente de trabajadores en el mundo. En la actualidad, como está quedando más claro por el impacto de la gran recesión de 2008-2009 y la «sacudida» que ha dejado atrás, podemos esperar que el precariado y la inseguridad laboral se incrementen.

Con escasa exageración, Peter Hall-Jones ha afirmado recientemente que «el precariado se está convirtiendo en la regla, no en la excepción» (HallJones, 2009). Durante décadas, la oIt ha utilizado la categoría de trabajo atipico, pero ¿realmente ha captado la nueva norma del trabajo contingente, precario e inseguro? Ello implica que si luchamos por trabajo decente, de algún modo la norma previamente existente de trabajo típico podría restablecerse junto con relaciones tripartitas estables entre los sindicatos, el gobierno y los patrones. De hecho, es de dudarse que la visión del mundo del trabajo de la ort alguna vez fuera exacta siquiera para las tierras de la democracia social en Escandinavia en el clímax del boom de la posguerra. Ciertamente, en la actualidad, prevalece lo atípico en la forma de desempleados, de trabajadores por su propia cuenta, de campesinos de subsistencia, de trabajadores desarraigados y otras formas similares.

Volviendo ahora a Brasil, ¿cómo han respondido los sindicatos a la informalización y al surgimiento del precariado? Recuérdese que en los años ochenta Brasil encabezó uno de los más fuertes movimientos sindicales en el 
mundo, que dio lugar al Partido de los Trabajadores y a Lula, el presidente de los trabajadores entre 2003 y 2010. El desarrollo capitalista en Brasil durante los años noventa derivó en una considerable reestructuración laboral con mayor trabajo maquilado (outsourcing), trabajo en los hogares y especialización flexible en el sector formal. Aunque los sindicatos han conservado la capacidad de movilizar a los trabajadores en el sector moderno, se han visto fuertemente desorientados por el proceso de reestructuración. Las tasas de empleo en el sector formal han descendido y asimismo la membresía sindical. En las firmas subcontratadas, en particular, el gobierno de la gerencia es absoluto y la frontera del control se encuentra más allá del alcance de los sindicatos. Decir que esto ha generado un momento difícil para los sindicatos seguramente es un eufemismo.

Según lo expresa José Ricardo Ramalho: «la precariedad del trabajo se ha difundido en Brasil y la mayor parte de los sindicatos ha sido incapaz de desarrollar nuevas acciones. De hecho, incluso su sobrevivencia como organizaciones colectivas está en juego» (Ramalho, 1999: 171). Aun cuando la fuerza de trabajo organizada en Brasil está en la posibilidad bastante rara de señalar al Partido de los Trabajadores como su representante, su influencia en el mundo del trabajo se ve cada vez más limitada por la reestructuración y el aumento del precariado. Hay sectores sindicales que han ido más allá del corporativismo y han asumido los problemas más amplios del trabajo, incluyendo a aquellos sectores no organizados por los sindicatos. A este respecto, lo que probablemente sea necesario para responder a la actual crisis es una revitalización del tipo de orientación practicada por el emergente sindicato de trabajadores metalúrgicos a fines de los años setenta con su práctica del «sindicalismo de movimiento social», desarrollado de manera holística, incluyendo el contexto de la comunidad y no sólo el espacio del lugar de trabajo.

Ciertamente, es muy frecuente que los sindicatos sean burocráticos ( $c f r$ la famosa «ley de hierro de la oligarquía» de Michel); ciertamente pueden firmar «tratos de amor» con los patrones y pueden a veces desarrollar relaciones corruptas con los gobiernos. Sin embargo, casi universalmente se 
han visto severamente afectados en los últimos 25 años de reestructuración del capital y la descomposición de la fuerza de trabajo. A pesar de sus fallas, yo argumentaría que los sindicatos siguen siendo la principal expresión colectiva de los intereses de los trabajadores y conservan, aunque sea de manera desigual, la capacidad para reinventarse y desempeñar un papel positivo para la transformación social. Aunque la respuesta de los sindicatos nunca ha sido lenta en lo que se refiere a los cambios estructurales en el mundo del trabajo, podemos ahora hacer notar un concertado intento de ir más allá de los bastiones del empleo formal. Así, en muchos países vemos a los sindicatos organizar a los trabajadores independientes (freelance) (por ejemplo, los principales sindicatos mediáticos en Canadá), trabajadores de agencias (en la mayoría de los países escandinavos), los autoempleados (Holanda), las mujeres autoempleadas (Asociación de Mujeres Autoempleadas en India), los trabajadores migrantes (España e Italia) y, por supuesto, el creciente ejército de desempleados (en muchos países). Vemos cuando menos la posibilidad de trasladarse más allá de la corriente burocrática dominante y del movimiento de trabajadores disperso y carente de poder.

\section{Movimiento de los trabajadores}

Un espectro recorre el mundo y es el espectro de la migración. Todos los poderes del viejo mundo están aliados en una operación sin misericordia en contra de él, pero el movimiento es incontenible (Hardt y Negri, 2000).

El espectro del comunismo ya no recorre el mundo, ahora su papel ha sido asumido por el precariado global en el movimiento que acompaña lo que Hardt y Negri llaman su «deseo irrefrenable de libre movimiento» (Hardt y Negri, 2000: 213). Aun cuando el éxodo puede verse sin duda como una forma poderosa de lucha de clase en contra del nuevo orden imperial, todavía es una forma manifiestamente espontánea de lucha no intencionada. La movilidad y la migración son vistas como una ruptura en los constreñimientos 
disciplinarios bajo los cuales operan los trabajadores y por ende son vistas como positivas. Ciertamente, la clase trabajadora está en movimiento de muy diversas formas y su administración está aparentemente más allá de los más rigurosos controles fronterizos de la mayor parte de los Estados capitalistas.

En un nivel más prosaico, la migración puede ser vista como una parte integral de la regulación del mercado de trabajo en la era de la globalización. Es claro que las economías del alguna vez pudiente Norte todavía dependen, en gran medida, de la rápida disponibilidad de la fuerza de trabajo migrante. Estos trabajadores, en la mayoría de las ocasiones, son vulnerables y muchos de los derechos laborales básicos simplemente no se les aplican. Como señala Harold Bauder, «la migración internacional es una herramienta de regulación del mercado de trabajo» (Bauder, 2006: 4) que permite a los patrones reducir los salarios y los estándares laborales por medio de la introducción de una fuerza de trabajo «barata y flexible». ¿Estamos viendo emerger aquello a lo que Pierre Bourdieu se refirió como un «ejército global de reserva de fuerza de trabajo»? (Bourdieu, 2002: 40) Si es ése el caso, debería interesar a los movimientos sindicales el responder con una política inclusiva hacia los trabajadores migrantes y no por medio de un proteccionismo nacional como ha sucedido con bastante frecuencia en el pasado (véase Penninx y Roosblad, 2000), aun cuando a veces se olvida esto.

El precariado como concepto, que discutimos en la sección anterior, se está manifestando ahora por medio del surgimiento de un nuevo trabajador global precario por medio de la migración en una época de recesión. Ellos son quizá la avanzada de la ofensiva capitalista neoliberal en contra de los estándares laborales. Ahora, los movimientos sindicales y otros movimientos sociales pueden, por supuesto, responder de diferentes formas. Pueden incorporar a estos trabajadores en sus organizaciones y presionar para que se igualen los estándares laborales en oposición a la «carrera hacia el fondo» del neoliberalismo o, inversamente, pueden ir de la mano con el discurso dominante racista y xenófobo y encabezar activamente la ofensiva de exclusión en el lugar de trabajo. Sin embargo, la precariedad — como se da en la infor- 
malización y en la irregularización - no debe entenderse como una simple oposición binaria a un estatus mítico estable-formal-regular del trabajador, sino como un proceso con muchos gradientes y dimensiones que afectan a todos los trabajadores (véase Goldring y Landolt, 2011).

El trabajo precario tiene un paralelo en un estatus de ciudadanía precaria para muchos migrante en la actualidad. El ejemplo de los sans papier (indocumentados) en Francia constituye un ejemplo preclaro de esta nueva fuerza de trabajo móvil, temporal y prescindible. De hecho, podríamos argumentar que las categorías de ciudadanía probablemente sean la principal fuente de división dentro de la fuerza de trabajo global. La segmentación del mercado de trabajo puede correlacionarse directamente con un estatus de ciudadanía diferencial. Van Parijs llega a decir que este estatus de ciudadanía ha ejercido, en términos cuantitativos, una influencia más poderosa en la distribución del bienestar material que el estatus de riqueza o habilidades (Van Parijs, 1992: 162). Ciertamente podemos ver un movimiento concertado desde 2001 (el «9-11» y la llamada "guerra contra el terror») hacia lo que sólo puede llamarse la irregularización de la ciudadanía (véase Nyers, 2010), ya que las fronteras que alguna vez fueron seguras entre el ciudadano y el no ciudadano se hacen nebulosas y el Estado de excepción se convierte en la norma.

La pregunta obvia entonces es ¿qué debe hacerse? Podríamos hacer un llamado a la re-regulación del mercado de trabajo como hacen algunos sectores capitalistas lúcidos en relación con las finanzas. La campaña de la OIT del trabajo decente ofrece una respuesta aparentemente coherente a la situación del precariado global. Muchos gobiernos nacionales y la Oficina Internacional de la Migración están comprometidos con ofrecer una ruta clara para el acceso a la ciudadanía para los migrantes. No obstante, al reflexionarlo más en detalle, «administrar la migración» como un proyecto global constituye un elemento integral de la nueva estrategia neoliberal para salvar al globalismo del capitalismo financiero no regulado. En realidad no existió una era dorada en que los derechos laborales para todos se respetaran como un estado de cosas al que ahora pudiéramos simplemente regresar. Lo que permite la crisis 
global de 2008-2009, empero, es una oposición más ampliamente legítima a «no hay alternativa» como una verdad aceptada y la (re)construcción de una perspectiva laboral democrática en la cual se sincronicen las perspectivas global, regional, nacional y local.

La crisis económica global está teniendo un efecto de gran importancia en el movimiento de los trabajadores más allá de las fronteras nacionales y no podemos predecir cuál será el resultado final. En el pasado, el reclutamiento de trabajadores migrantes ha sido altamente susceptible ante el ciclo económico. Desde 2008-2009, ciertamente hemos visto una disminución especialmente en la migración irregular y una caída aguda en las remesas económicas. Las industrias en las que predominaban los migrantes, como la construcción y los servicios, han sido particularmente vulnerables a la recesión económica global. Sin embargo, ahora parece quedar claro que no podemos trazar simples paralelos con la depresión de los años treinta o siquiera con la crisis capitalista occidental del año 1973 en términos de su impacto en los trabajadores migrantes. Esto no lo es menos por el hecho de que el mundo de 2008-2009 estuviera mucho más integrado de lo que estuvo, digamos, hace veinte años o incluso hace diez años, de modo que la recesión económica es más global y no hay un evidente refugio seguro para que regresen los migrantes.

La globalización ha creado un mundo económica, social y espacialmente mucho más integrado que nunca antes. Las diásporas de la fuerza de trabajo han formado densas redes sociales integradas íntimamente en la expansión espacial de este nuevo capitalismo global. Es a través de estas redes, como lo expresa David Harvey, que «vemos ahora los efectos de la caída financiera que se expande hasta casi todos los rincones y recovecos del África rural o de la India agrícola» (Harvey, 2010: 147). El impacto de este develamiento en términos de su impacto en las remesas económicas, que ahora se consideran cruciales para el desarrollo, es un tema particularmente sensible. El régimen de la gobernanza global posterior a la crisis bien podría captar esta particular madeja. Ciertamente, como lo expresan Castles y Vezzoli, podríamos ver «nuevos patrones de migración, nuevos países de origen 
y de recepción y el surgimiento de un nuevo orden de la migración» (Castles y Vezzoli, 2009: 74). Cualesquiera que sean las variantes que surjan en la práctica, al menos es cierto ahora que la migración no es un flujo que pueda abrirse o cerrarse con un grifo de políticas.

De existir un Estado global verdaderamente efectivo o, en todo caso, un movimiento de trabajadores global reconocido, necesariamente abordaría el tema de los migrantes globales. Por el momento, el traslado de personas parece poco probable que sea sujeto de la regulación que, por ejemplo, la Organización Mundial de Comercio (omc) busca imponer al comercio. Sin embargo, según Natasha David, «en respuesta a la globalización económica, los sindicatos están organizando la globalización de la solidaridad en defensa de los migrantes» (David, 2002: 74). Con toda seguridad, esto ocurre de manera desigual en el planeta. Los sindicatos sudafricanos reaccionaron de manera decidida en contra de la persecución de los migrantes en ese país en 2008. Los sindicatos franceses, por otra parte, algunas veces han estado al frente de los ataques a los migrantes, sin reparar en que la migración es inevitable y que resulta imposible construir un sindicato coherente y una estrategia democrática de renovación al margen de los migrantes.

El compromiso de los sindicatos con los trabajadores migrantes se abordará plenamente en la siguiente sección en la que se exploran diversas formas de sindicalismo social y comunitario. Pero siguiendo en el tema de los trabajadores en tránsito, quiero recordar que la mayor parte de la migración es interna y también internacional. De tal modo, mientras que probablemente haya unos 200 millones de migrantes transnacionales en la actualidad (es decir, personas que viven fuera de su país de origen), probablemente haya unos 100 millones de migrantes internos en China y una abrumadora cantidad de 300 millones (30\% de la población) en India. Debemos entonces ser precavidos al situar una rígida barrera conceptual entre los migrantes nacionales e internacionales. La «era de la migración» también es, claramente, una era de movimientos masivos de población dentro de los países en el Sur global, el que será probablemente el espacio de la siguiente etapa de la acumulación global de capital. 
La migración —en toda su complejidad— está por ende íntimamente ligada a las perspectivas de desarrollo global. Los gobiernos nacionales se enfocan actualmente en el nexo entre la migración internacional y el desarrollo, el tema de las remesas económicas, la llamada fuga de cerebros y la posible promoción de la migración circular. Desde una perspectiva de los movimientos sindicales y sociales, la migración interna —especialmente en el Sur globalhabría de verse como igualmente importante. Históricamente, muchos movimientos sindicales en el Sur se construyeron, precisamente, a partir de la incorporación de los migrantes internos en el movimiento de los trabajadores. Ellos se convirtieron en los principales impulsores del desarrollo — por medio de su fuerza de trabajo- y también en los promotores clave de la democracia y la liberación nacional. En la época actual, la promoción necesaria del internacionalismo laboral no debería (argumento) evitar la participación del movimiento de los trabajadores en la promoción del desarrollo nacional democrático en aquellas partes del mundo impactadas negativamente, histórica y actualmente, por la incorporación desigual y dependiente en la economía global.

\section{UNA FUERZA DE TRABAJO QUE RESURGE}

En su esencia, el capital es global. Como regla, la fuerza de trabajo es local [...] El trabajo es desagregado en su desempeño, fragmentado en su organización, diversificado en su existencia, dividido en su acción colectiva (Castells, 1996: 475).

En un volumen subsecuente, Castells expresa su posición en términos aún más categóricos: «el movimiento de los trabajadores parece haber sido superado históricamente» (Castells, 2004: 425). En la primera sección de este artículo hemos analizado el proceso de informalización, que sin duda desagrega la fuerza de trabajo y fragmenta a sus organizaciones. En la sección 
que analiza a los trabajadores en tránsito hemos mostrado que aunque el trabajo bien podría ser predominantemente local, también se mueve dentro de los países y entre ellos. Lo que en esta sección se abordará es el desafío más amplio que plantea Manuel Castells, a saber, que el movimiento de los trabajadores en la actualidad ha sido superado efectivamente en la era del capitalismo estructurado en red.

Podemos comenzar por reconsiderar el papel contradictorio de los sindicatos en las sociedades capitalistas. Perry Anderson escribió alguna vez que «los sindicatos son esencialmente una representación de facto de la clase trabajadora en su lugar de trabajo» (Anderson, 1977: 335). Dentro de los parámetros de la división capitalista del trabajo, la única arma de los trabajadores es la de la ausencia (la huelga). En contraposición con esta visión negativa (que sin duda refleja cierta realidad social), podemos ubicar una visión de los sindicatos como escuelas a favor del socialismo y defensores de los pobres. Gerald Friedman en Reigniting the Labor Movement se ha referido recientemente a la manera en que el movimiento de los trabajadores ha estado, por más de un siglo, «construyendo de fuerza en fuerza, haciendo a la sociedad más democrática, más respetuosa de los pobres, trasladando a los derechos humanos por encima de los reclamos de la propiedad capitalista» (Friedman, 2008: 10). Ciertamente, esta visión parece estar muy lejana de la visión negativa que esbozamos antes, pero quizá es contradictoria sin ser incompatible con la visión clásica del sindicalismo economicista. Hay un viejo cartel sindical de los años veinte donde se muestra a un sindicalista con dos caras: una enterrando a un capitalista y otra actuando como su doctor. Tal es la contradicción del sindicalismo bajo el capitalismo.

También necesitamos entender que los sindicatos no comenzaron completamente formados, con oficinas nacionales y con estructuras burocráticas. Desde el inicio, la dimensión internacional fue crucial y los trabajadores migrantes ocupaban un lugar central. Como lo expresa Van der Linden, «los impresores y los mineros fueron pioneros [en la formación de los secretariados internacionales de los gremios - International Trade Secretariats - en la déca- 
da de 1860]» (Van der Linden, 2003: 158). Los impresores eran trabajadores capacitados y móviles con membresías en conexiones transnacionales de largo tiempo atrás. Los mineros británicos tendían a establecer una alianza internacional con sus contrapartes europeas dado que sus condiciones y salarios eran mejores. La libre migración a través de las fronteras era considerada natural y era poco frecuente la xenofobia; el internacionalismo en sus sentidos económico y político era, por ende, un desarrollo natural. Este primer internacionalismo vivió poco, empero, ya que la formación de los Estados comenzó a encabezar la integración nacional de las clases trabajadoras europeas en particular.

Así, en un cierto punto de la historia, los sindicatos fueron, podría decirse, «nacionalizados» en el sentido de convertirse en un elemento integral de la cohesión social y política dentro de los límites de un determinado Estadonación. Para cuando se desató la Primera Guerra Mundial en 1914, esta integración nacional derivó en un colapso casi total del internacionalismo de los trabajadores y socialistas en Europa. A partir de entonces, las organizaciones nacionales y la búsqueda del mejoramiento social a través del Estado-nación se convirtió en la modalidad dominante del sindicalismo. El internacionalismo quedó relegado a las peroratas rituales en los congresos sindicales.

El sindicalismo nacional (e incluso nacionalista) adoptó una complexión diferente en el Sur global. Ahí, en especial después de la Segunda Guerra Mundial, los sindicatos se convirtieron, en muchos casos, en componentes vitales de los movimientos nacionales de liberación en África y Asia, mientras que en América Latina impulsaron el desarrollo económico nacional. Dada la naturaleza asimétrica del sistema mundial —colonialismo, imperialismo, globalización - esta contradicción difícilmente es sorprendente y siempre tenemos que poner al frente la división Norte/Sur, incluso si nos movemos más allá de ésta en términos de categorías y estrategias analíticas.

En la actualidad, tras cerca de 25 años de lo que hemos llamado globalización, podemos (re)considerar si los sindicatos y el movimiento de los trabajadores son obsoletos como cree Castells. Para comenzar, la cantidad de trabajadores se ha incrementado exponencialmente en esta etapa dinámica de 
crecimiento capitalista de cerca de 1.8 miles de millones en 1980 a una cantidad que se estima alcanzará los 3.6 miles de millones en 2020 (ort, 2004). Aun cuando los sindicatos nacionales han decaído en membresía en la mayor parte de los países, el sindicalismo internacional está más unido políticamente que en cualquier momento desde sus orígenes. Mi propio análisis (véase Munck 2010, 2011) me lleva en la misma dirección que Peter Evans, quien ha argumentado recientemente que estamos viendo «un arco ascendente de movilización transnacional más que una especie de precipitado declive que se predice en la tesis de la Némesis» (Evans, 2010: 367). Que haya habido un lapso de 25 años entre la ofensiva capitalista y la recomposición de la fuerza de trabajo no es de sorprender y se ajusta al patrón de las oleadas de los siglos XIX y xx de recomposición de la fuerza de trabajo (véase Arrighi, 1996).

Vemos ahora claros movimientos hacia la revitalización sindical en casi todo el planeta. Hay una clara comprensión de que la globalización y sus impactos son el tema clave para los sindicatos en todas partes. Los nuevos lazos que trascienden las fronteras nacionales proliferan en los niveles globales y regionales (por ejemplo, el Tratado de Libre Comercio de América del Norte, la Unión Europea, el Mercado Común del Sur, entre otros). En la actualidad, es evidente una mucho mayor interacción con los movimientos sociales y también con las organizaciones no gubernamentales, por ejemplo en torno a los derechos laborales. La creciente literatura académica sobre la revitalización sindical ha encontrado avances en las áreas estratégicas de organización de nuevos sectores, mayores acciones políticas, reforma de las estructuras sindicales, establecimiento de coaliciones y, finalmente, pero no menos importante, solidaridad internacional (Frege y Kelly, 2004). De manera muy similar al nuevo sindicalismo de fines del siglo xIx, que alcanzó a los trabajadores no calificados y semicalificados, más que a la élite de trabajadores calificados, a las mujeres trabajadoras y no sólo a los hombres, el nuevo sindicalismo se reconstruye para salvarse de la obsolescencia.

El sindicalismo como movimiento social constituyó una estrategia particular de los sindicatos impulsado principalmente por los sindicatos del Sur en 
los años ochenta. Mientras que el sindicalismo económico se centraba en los trabajadores como vendedores de fuerza de trabajo y el sindicalismo político se centraba en el Estado-nación para hacer avanzar la causa de los trabajadores, el sindicalismo social reconocía que los trabajadores eran parte de la sociedad y tenían que organizarse más allá del lugar de trabajo. En Sudáfrica, bajo el apartheid y en Brasil bajo la dictadura militar, el nuevo sindicalismo floreció más claramente. En los años ochenta, los sindicatos buscaron aliarse dentro de una comunidad más amplia, con grupos eclesiales y con campañas monotemáticas. Un equivalente democrático fue el común denominador y también floreció la democracia dentro de los sindicatos. Para fines de los años noventa, algunos analistas demandaban un «sindicalismo como movimiento social global» (Moody, 1997). En un contexto diferente, esta iniciativa encabezada desde el Sur se dirigía a «ser parte de la corriente dominante» y ser adoptada por los movimientos sindicales que alguna vez fueron conservadores.

Una de las formas más espectaculares de revitalización sindical ha ocurrido en Estados Unidos, el que alguna vez fue el epítome del sindicalismo empresarial. En 1995, la victoria de la planilla Nerw Voice de John Sweeney marcó un punto de inflexión decisivo en la política laboral de Estados Unidos y abrió las puertas para una nueva forma de pensar. Fue en relación con el sindicalismo comunitario — enfocado en los trabajadores migrantes en particular- que la reavivación del movimiento laboral en Estados Unidos encontró muchas de sus más claras expresiones (véase Ness, 2005). Los sindicatos comunitarios en el contexto de Estados Unidos parecen ser de pequeña escala, sirviendo de puente o mediación entre instituciones con sede en comunidades específicas en vez del lugar de trabajo. Por ende, no son sindicatos en el sentido tradicional sino que surgen de los movimientos de solidaridad, de los movimientos con fundamento en la fe o de grupos de servicios legales o sociales. Conscientes de la abrumadora importancia del estatus legal para los trabajadores migrantes, estos tienden, como lo expresa Janice Fine, «tanto a enfocar gran atención en organizarse para cambiar la política de inmigración como pueden hacerlo en los temas del mercado de trabajo» (Fine, 2005: 154). 
También hay clara evidencia en Estados Unidos de que las personas pobres se están sindicalizando y que los sindicatos han aprendido algunas lecciones de los movimientos locales de mujeres, afroamericanos, campesinos mexicanos y demás. Como lo expresa Vanessa Tate, «los sindicatos de "trabajadores pobres" [...] valoran la acción directa, la flexibilidad y la colaboración [...] sobre los métodos burocráticos y legalistas en los que con frecuencia han confiado los sindicatos tradicionales» (Tate, 2005: 310). En la actual recesión económica se ejercerá una enorme presión en las alianzas sociales y el proteccionismo, por lo seguro, será una reacción esperada. Hay signos, empero, de que continuará la fusión de la clase trabajadora y los nuevos movimientos sociales y «la siguiente marejada», como la llama Dan Clawson, verá «una combinación del compromiso y de la representatividad democrática de los sindicatos con la imaginación y la energía de los nuevos movimientos sociales» (Clawson, 2003: 196). Si esto se materializa, entonces el sindicalismo, de movimiento social en el Sur de los años ochenta, habrá encontrado un valioso sucesor en el Norte. La fuerza de trabajo se habrá movido «más allá del Norte y del Sur» en la misma medida en que lo ha hecho de manera tan efectiva el capital globalizante.

En Gran Bretaña se han dado también movimientos extremadamente interesantes hacia lo que ellos llaman sindicalismo comunitario. El énfasis se dio en asegurar nuevos miembros y utilizar nuevos métodos organizacionales. Al ir más allá del lugar de trabajo y de los mecanismos tradicionales de negociación colectiva, algunos sindicatos, en especial en la capital, Londres, comenzaron a acercarse particularmente a los trabajadores migrantes no organizados. La campaña del salario mínimo en Londres lanzada en 2001 vio un intenso trabajo de base y, dentro de los sindicatos, la creación de un «sindicalismo comunitario» que apoyaba en la capital a los trabajadores de bajos salarios que en su mayor parte eran migrantes. Los sindicatos fueron lentos para unirse a lo que se ha descrito como «organizaciones ad hoc, espontáneas, localizadas o de base geográfica con socios locales» (Holgate, 2009: 66), pero la inercia burocrática fue superada y, en el proceso, pudo descubrirse el vislumbre de un nuevo 
sindicalismo. Como lo expresa Jane Wills, este nuevo sindicalismo comunitario en el Reino Unido por el momento es incipiente, pero está permitiendo a los sindicatos encontrar una causa en común con grupos cohesionados en torno a afiliaciones religiosas, étnicas o de otro tipo, «vinculando efectivamente la lucha por la redistribución con eso y el reconocimiento, lo universal con lo particular, lo económico con lo cultural» (Wills, 2001: 469).

Al examinar el pasado vimos una época prenacional de generación del movimiento laboral; al atisbar hacia el futuro, ¿podemos anticipar una mayor renovación o revitalización de la fuerza de trabajo como un movimiento social? Primero, necesitamos reconocer, como hizo Karl Polanyi contra todos los apologistas, que el propósito de los sindicatos es «exactamente el de interferir con las leyes de la oferta y la demanda con respecto a la fuerza de trabajo humana y retirarla de la órbita del mercado» (Polanyi, 2000: 186). Si la desmercantilización del trabajo - más que obtener el mejor precio por la fuerza de trabajo- se convierte en la fuerza motriz de los sindicatos, entonces se encontrarán al frente de un contra-movimiento global social de resistencia más amplio en contra de las depredaciones del mercado no regulado. Esto tendría que pasar en todos los niveles de la actividad humana desde lo local a lo global. En la medida en que los sindicatos y el más amplio movimiento de los trabajadores adopten esta tarea, comenzarán a plantear una alternativa contrahegemónica una vez más.

\section{Consideraciones Ulteriores}

Al recorrer las anteriores reseñas de la informalización, la migración y la revitalización sindical, acuden a la mente algunos pensamientos generales:

1) Hemos ido más allá de una concepción del Norte y del Sur que los veía como si fueran universos separados con formas de desarrollo capitalista que eran fundamentalmente diferentes o sujetas a diferentes 
leyes de movimiento. La oleada de crecimiento de los últimos 25 años del capitalismo global ha producido, para bien o para mal, un sistema claramente unificado, aunque sujeto a un desarrollo desigual. El hecho se corrobora por la recesión global de 2008-2009 donde literalmente no hubo lugar para que se refugiaran ni el capital ni los trabajadores.

2) El capitalismo no es, empero, un monolito y sus patrones de desarrollo son altamente contradictorios. No lo es menos por el hecho de que esta última etapa dinámica asociada con la globalización ha generado una expansión considerable del movimiento de la clase trabajadora. Aun cuando los trabajadores no son necesariamente los sepultureros del capitalismo, su interés social (no menos el de sobrevivir) los coloca en oposición al orden dominante. Esto ofrece, cuando menos, una oportunidad para la revitalización sindical.

3) La globalización ha abierto tantas puertas como las que ha cerrado para los movimientos sociales que surgen como consecuencia y en contraposición a la expansión de un mercado regulado. Esto no significa que sólo una respuesta global de la clase trabajadora será suficiente para oponerse al orden capitalista global. Una respuesta integrada en múltiples escalas, desde lo local, pasando por lo subregional, lo nacional y de lo regional a lo global, podrá oponerse, en conjunto, al supuesto conocimiento capitalista superior respecto a lo que es mejor para la humanidad, pero será más efectiva cuando el movimiento global de los trabajadores sea capaz de ofrecer un liderazgo y trascender las reacciones defensivas.

4) La voluntad política y la toma de decisiones son ahora cruciales y nada está ordenado de antemano en este interregno inestable del orden capitalista global. También la izquierda asume con frecuencia que el capitalismo es más coherente y visionario de lo que es. Cualesquiera obstáculos estructurales que existan, la agencia social y política siguen teniendo peso.

5) Para dar un ejemplo a nivel nacional, la clase trabajadora de Argentina casi se duplicó en tamaño entre 1930 y 1945 como consecuencia de la industrialización de sustitución de importaciones. Los socialistas y los 
comunistas en los sindicatos le dieron la espalda a los migrantes internos que crearon la nueva clase trabajadora. Un desconocido oficial del ejército, Juan Perón, recibió la ayuda únicamente del sector sindicalista y desde entonces hemos tenido una clase trabajadora peronista. Las cosas podían haber sido de otro modo.

6) La migración laboral será utilizada inevitablemente por los capitalistas para debilitar los estándares laborales. El precariado tiende a convertirse en una norma global y su surgimiento sin duda generará enormes tensiones en el movimiento organizado de los trabajadores.

7) Sin embargo, la nueva migración también constituye una enorme oportunidad para el movimiento de los trabajadores. Si practica la creencia en que «el internacionalismo comienza en casa», recluta migrantes y apoya su causa, asumirá el manto más amplio de la transformación democrática.

8) La estrategia del movimiento de los trabajadores que representa mayor riesgo en la actualidad sería, de hecho, la de «sin novedad» y una esperanza de que el servicio normal se restablecerá pronto. Ahora la decisión prudente es apropiarse del momento, asumir los riesgos, buscar alianzas previamente inauditas (como la de Teamsters y Turtles en Seattle en 1999) y ver qué une a los contra-movimientos sociales de resistencia más amplios, en vez de qué los separa.

9) No es momento ahora de defender intereses creados o confiar en el proteccionismo de cualquier tipo. En cambio, hay necesidad frente a un orden dominante en decadencia, pero cada vez más desesperado de apoyar una agenda más amplia de democratización. Lo que está en juego ahora es mucho más valioso y necesitamos ser firmes, esperando recuperar parte del fervor de la organización de los trabajadores en los primeros tiempos y el surgimiento del nuevo sindicalismo.

10) El sindicalismo como movimiento social no constituye una panacea y no puede ofrecer un cartabón para todas las situaciones nacionales. Sin embargo, el movimiento organizado de los trabajadores necesita 
reconocer las limitaciones tanto de una estrategia economicista de la fuerza de trabajo como de un sindicalismo político empecinado, que pone su fe en reformar al Estado. Al hacerlo, necesitará explorar el rico repertorio del sindicalismo social y comunitario.

\section{ReFERENCIAS}

Anderson, Pierre (1977), «The limits and possibilities of trade union action» en T. Clarke y L. Clements (editores), Trade unions under capitalism, Londres, Fontana.

Arrighi, Giovanni (1996), «Workers of the world at century's end», Revierw, volumen XIX, número 3.

BAuder, Harald (2006), Labor movement. How migration regulates labor markets, Oxford, Oxford University Press.

Beck, Ulrich (2009), The brave new world of work, Cambridge, Polity Press. Bourdieu, Pierre (2002), «Against the policy of depoliticization», Studies in Political Economy, número 69.

Castells, Manuel (1996), The rise of the network society, Oxford, Blackwell. (2004), The power of identity, Oxford, Blackwell.

Castles, Stephen y Simona Vezzoli (2009), The global economic crisis and migration: Temporary interruption or structural change, http://www. emi.ox.ac.uk> (consulta: 22 noviembre de 2010).

Clawson, Dan (2003), The next upsurge: Labor and the new social movements, Ithaca y Londres, Cornell University Press.

DAvid, Natacha (2002), «Migrants get unions back to basics», Labour Education, Geneva, ILO, número 129.

Davis, Mike (2007), Planet of slums, Londres y Nueva York, Verso.

Evans, Peter (2010), «Is it labour's turn to globalize? Twenty-first century opportunities and strategic responses», Global Labor Journal, volumen 1, número 3. 
Fine, Janice (2005), «Community unionism and the revival of the American labor movement», Politics and Society, volumen 33, número 1.

Frege, Carola y John Kelly (editores) (2004), Varieties of unionism: Strategies for union revitalisation in a globalising economy, Oxford, Oxford University Press.

Friedman, Gerry (2008), Reigniting the labour movement. Restoring means to ends in a democratic labour movement, Londres y Nueva York, Routledge.

Goldring, Luin y Patricia Landolt (2011), «Caught in the work-citizenship matrix: The lasting effects of precarious legal status on work for Toronto immigrants», Globalizations, volumen 8, número 3.

Hall-Jones, Peter (2009), «Precariat meet'n'greet», http://www.newunionism.worldpress.com/2009/11/22/precariat/\#more-3767> (consulta: 20 de noviembre de 2010).

Hardt, Michael y Antonio Negri (2000), Empire, Cambridge Mass y Londres, Harvard University Press.

HarT, Keith (1973), «Informal income, opportunities and urban employment in Ghana», The Journal of Modern African Studies, número 11.

Harvey, David (2010), The enigma of capital and the crisis of capitalism, Londres, Verso.

Holgate, Jane (2009), «Contested terrain: London’s living wage campaign and tensions between communities and union organising» en Jo McBride y Ian Greenwood (editores), Community unionism. A comparative analysis of concepts and contexts, Londres, Palgrave.

ILO, LABORSTA (2004), http://laborsta.ilo.org/> (consulta: noviembre de 2010). Moody, Kim (1997), Workers in a lean world. Unions in the international economy, Londres y Nueva York, Verso.

Munck, Ronaldo (2010), «Globalisation and the labour movement: Challenges and responses», Global Labour Journal, volumen 1, número 2. (2011), «Unions, globalisation and internationalism: Results and prospects» en G. Gall, R. Hurd, y A. Wilkinnon (editores), International handbook on labour unions, Londres, Elgar. 
Ness, Immanuel (2005), Immigrants, unions and the new us labor market, Filadelfia, Temple Unions Press.

NúN, José (1969), «Superpoblación relativa: ejército industrial the reserva y masa marginal», Revista Latinoamericana de Sociología, número 2.

Nyers, Peter (2010), «Forms of irregular citizenship» en Vicki Squire (editor), The contested politics of mobility: Borderzones and irregularity, Londres, Routledge.

Oliveira, Francisco de (1972), «A economía brasileira: crítica a razáo dualista», Estudos CEBRAP, número 2.

Penninx, Rinus y Judith Roosblad (editores) (2000), Trade unions, immigration in Europe, 1960-1993, Nueva York y Oxford, Berghann Books.

Polanyi, Karl (2000), The great transformation. The political and economic origins of our times, Boston, Beacon Press.

Ramalho, José Ricardo (1999), «Restructuring of labour and trade union responses in Brazil», en Ronaldo Munck y Peter Waterman (editores), Labour worldwide in the era of globalisation, Londres, McMillan.

TATE, Vanessa (2005), Poor workers' unions. Rebuilding labor from below, Cambridge, MA, South End Press.

VAn Der Linden, Marcel (2003), Transnational labour history, Aldershot, Ashgate.

VAn PARIJs, Philippe (1992), «Citizenship exploitation. Unequal exchange and the breakdown of popular sovereignty» en Brian Barry y Robert E. Goodin (editores), Free movement. Ethical issues with transnational migration of people and money, Hemel Hempstead, Harvester.

Wills, Jane (2001), «Community unionism and trade union renewal in the UK: moving beyond the fragments», Transactions of the Institute of British Geographers, volumen 26, número 4.

World Bank (1995), World development report: Workers in an Integrating World, Washington, World Bank and Oxford University Press. 